\title{
Sol-gel synthesis of tunable cerium titanate materials
}

\author{
Mónica Martos* ${ }^{[a]}$, Beatriz Julián-López, ${ }^{[a]}$ José Vicente Folgado, $^{[b]}$ Eloisa Cordoncillo ${ }^{[a]}$ and \\ Purificación Escribano $^{\text {[a] }}$
}

Keywords: Sol-gel processes/ Cerium/ Rare earth pyrocholore/ Titanates / Nanostructures

Cerium titanate structures present a high technologica
because of their optical and catalytic properties. This wo
the synthesis of these materials by a sol-gel methodolo
allows to obtain mixed oxides with Ti(IV)/Ce(III), Ti(IV)/Ce
$\mathrm{Ti}(\mathrm{IV}) / \mathrm{Ce}(\mathrm{III})-\mathrm{Ce}(\mathrm{IV})$ species. Crystallization of $\mathrm{CeO}_{2}-\mathrm{Ti}$
oxides and $\mathrm{Ce}_{2} \mathrm{Ti}_{2} \mathrm{O}_{7}$ pyrochlore phase has been corrob
$\mathrm{XRD}$ and Raman spectroscopy. Magnetic and EPR mea
have been performed in order to clarify the oxidation
cerium ions in the system, due to the easy oxidation of Ce(
[a] Departmento de Química Inorgánica y Orgánica
Universitat Jaume I de Castellón.
Avda. Sos Baynat s/n 12071 Castellón (Spain)
Fax: +34964728214
E-mail: mmartos@qio.uji.es
Instituto de Ciencia de los Materiales
Universidad de Valencia
Poligono de la Coma s/n, 46980 Paterna-Valencia (Spain)

\section{Introduction}

Pyrochlore oxides, $\mathrm{A}_{2} \mathrm{~B}_{2} \mathrm{O}_{7}$, are drawing a great deal of attention in many areas of materials science of technological interest because of their, frequently, unique properties induced by a remarkable chemical and structural flexibility. ${ }^{[1-3]}$ Thus, composition electroneutrality can be achieved by a large combination of cation species $\mathrm{A}$ and $\mathrm{B}$ with different oxidation states rendering a great variety of physical and chemical properties. ${ }^{[4]}$ Indeed, many properties of pyrochlores are very much influenced by ions distribution and site occupancies.

Among them, rare-earth titanates have become one of the best investigated rare-earth compounds in the past 40 years. Nevertheless, there are only a few investigations on RE-Ti-O systems $(\mathrm{RE}=$ rare-earth element $)$ dealing with the preparation of compounds containing $\mathrm{RE}=$ cerium. Indeed, it is difficult to prepare $\mathrm{Ce}$ (III) compounds at high temperatures due to the preference of the $\mathrm{Ce}(\mathrm{IV})$ oxidation state, contrary to the rare-earth elements tendency.

Some cerium titanates exist in the Ce-Ti-O system. Among them, it is known three cerium titanates involving mainly $\mathrm{Ce}^{3+},{ }^{5[}$ i.e., that is, the reddish-brown $\mathrm{Ce}_{2} \mathrm{TiO}_{5}$ and $\mathrm{Ce}_{2} \mathrm{Ti}_{2} \mathrm{O}_{7}$ and the chestnut $\mathrm{Ce}_{4} \mathrm{Ti}_{9} \mathrm{O}_{24}$, and two yellow cerium titanates with mainly $\mathrm{Ce}^{4+}$, $\mathrm{CeTiO}_{4}$ and $\mathrm{CeTi}_{2} \mathrm{O}_{6}$, which are formed when annealing cerium(III) titanates in air at high temperatures. ${ }^{[6]}$ Furthermore, numerous reports have studied the $\mathrm{CeO}_{2}-\mathrm{TiO}_{2}$ mixed oxide from its catalytic properties. ${ }^{[7-9]}$

$\mathrm{Ce}_{2} \mathrm{Ti}_{2} \mathrm{O}_{7}$ pyrochlore is formed by $\mathrm{Ce}^{3+}$ and $\mathrm{Ti}^{4+}$ ions in eight and six-fold coordination respectively. The ionic radii of $\mathrm{Ce}^{3+}$ and $\mathrm{Ti}^{4+}$
The firing atmosphere is crucial for the $\mathrm{Ce}(\mathrm{III}) / \mathrm{Ce}(\mathrm{IV})$ ratio which is responsible for the different structure, also affecting to the coloration (yellow, green, brown). This methodology offers the possibility to modulate the $\mathrm{Ce}^{3+} / \mathrm{Ce}^{4+}$ content and particle sizes providing more ecological coloured pigments based on rare earth elements which could be interesting materials for advanced applications in catalysis.

(C) WILEY-VCH Verlag GmbH \& Co. KGaA, 69451 Weinheim, Germany, 2007) ions in these coordinate sites are 1.283 and $0.745 \AA$. These values yield a ratio of 1.72 , which is within the tolerated range 1.46-1.8 for the pyrochlore structure. ${ }^{[10]}$ Nevertheless, the oxidation of $\mathrm{Ce}^{3+}$ to $\mathrm{Ce}^{4+}$ during thermal treatment derived from the intercalation of oxide ions gives species with an ionic radius of $1.11 \AA$. Since the radii of $\mathrm{Ti}^{4+}$ ions in eightfold coordination is $0.88 \AA$, the radii of the ions on the $\mathrm{A}$ and $\mathrm{B}$ sites converge and the oxide ion distribution more closely approaches to that in the fluorite structure. Several characterization techniques have been used in order to elucidate the pyrocholore to fluorite phase transition after oxidation of a pyrochlore structure. ${ }^{[11,12]}$

According to literature ${ }^{[13]}$ the oxidation of a $\mathrm{Ce}^{3+}$ pyrochlorerelated structure may proceed smoothly at a low temperature, maintaining the ordered arrangement of the constituent cations, but with $\mathrm{Ce}^{3+}$ and $\mathrm{Ce}^{4+}$ ions. The cerium oxidation process has an important influence in the final properties due to the creation of crystalline defects in the structure. Furthermore, the redox couple of $\mathrm{Ce}^{3+} / \mathrm{Ce}^{4+}$ together with the high capacity to store oxygen of cerium containing compounds are the basis of the wide application of $\mathrm{CeO}_{2}$ in heterogeneous catalysis. ${ }^{[14]}$

The oxidation process may be shown like an intercalation process,${ }^{[15]}$ which provides the ability to vary the composition and structure of solids in a controlled manner often at temperatures below those usually used in solid state synthesis. Furthermore, such metastable intercalation compounds often exhibit unusual but desirable electrical, magnetic and optical properties.

The pyrochlore oxidation has also been researched in the $\mathrm{CeO}_{2}$ $\mathrm{ZrO}_{2}$ mixed oxides system. Yashima et al. ${ }^{[16]}$ have reviewed the phase diagram and phase transition in the $\mathrm{CeO}_{2}-\mathrm{ZrO}_{2}$ system. In the Ce-rich area a cubic phase is detected, meanwhile in the $\mathrm{Zr}$-rich area the monoclinic phase is stabilized. At intermediate compositions, it is proposed the existence of three tetragonal phases with different tetragonal distortion. In addition to the tetragonal phases, a $\kappa-\mathrm{CeZrO}_{4}$ phase appears by oxydizing the pyrochlore-type $\mathrm{Ce}_{2} \mathrm{Zr}_{2} \mathrm{O}_{7+2 \delta}$ phase at $873 \mathrm{~K},{ }^{[17]} \mathrm{Ce}$ and $\mathrm{Zr}$ ions in the $\kappa$ phase are in an ordered arrangement similar to the arrangement in the pyrochlore-type phase. $\mathrm{CeZrO}_{4}$ fluorite 
structure is formed by oxygen insertion in the pyrochlore oxygen vacancies and the consequent oxidation of $\mathrm{Ce}^{3+}$ to $\mathrm{Ce}^{4+}$ ions.

Similar to the appearance of $\kappa$-type $\mathrm{CeZrO}_{4}, \mathrm{CeTiO}_{4}$ phase results from the oxygen insertion in the $\mathrm{Ce}_{2} \mathrm{Ti}_{2} \mathrm{O}_{7}$ phase, retaining the arrangement of $\mathrm{Ce}$ and $\mathrm{Ti}$ ions, although the $\mathrm{CeTiO}_{4}$ structure has not been yet clarified. For cerium titanates, the defects related to oxygen, e.g., oxygen vacancies, oxygen at interstitial vacancies and holes on the lattice oxygen may be considered as colour centres. ${ }^{[18]}$ This metastable phase could be related to a $\mathrm{CeO}_{2}-\mathrm{TiO}_{2}$ mixed oxide with 1:1 atomic ratio, which has been investigated by Reddy et al by various techniques. ${ }^{[19,20]}$

The optical features of cerium makes it a good candidate for colouring applications since the lowest $\mathrm{Ce}^{3+} 4 \mathrm{f}^{1} \rightarrow 5 \mathrm{~d}^{1}$ absorption transition takes place in the blue spectral region leading to a yellow-orange body colour. As an example, $\mathrm{Ce}^{3+}$-doped garnets present a yellow-orange colour, indicating that $\mathrm{Ce}^{3+}$ has been incorporated into the garnets. ${ }^{[21]}$ The blue radiation is strongly absorbed by the allowed $4 \mathrm{f} \rightarrow 5 \mathrm{~d}$ transition of $\mathrm{Ce}^{3+}$, leading to a yellow $5 \mathrm{~d} \rightarrow 4 \mathrm{f}$ (to the spin-orbit split ${ }^{2} \mathrm{~F}_{7 / 2}$ and ${ }^{2} \mathrm{~F}_{5 / 2}$ levels) emission band. ${ }^{[22]}$ The coloration of titanates was adscribed to charge-transfer transitions in which an electron is transferred from the metal ion to the empty $3 \mathrm{~d}$ orbitals of the $\mathrm{Ti}^{4+}$ ion. By other hand, the presence of $\mathrm{Ce}(\mathrm{IV})$ ions can generate charge transfer bands which are also related to the colour mechanism, giving in this case a yellow coloration.

The conventional solid-state reaction traditionally used for the preparation of these materials involves laborious heating cycles at high temperatures with repeated grinding of the component oxides. The resulting powders show extensive agglomeration and compositional heterogeneity. However, electrical and optical properties are strongly influenced by the particulate morphology and compositional homogeneity. In order to avoid these problems, several chemical synthetic methods for the rare-earth pyrochlores have been developed. ${ }^{[23-25]}$ The principal benefits of solution synthesis techniques in contrast to conventional high-temperature solid state reactions include the high chemical homogeneity achieved on the molecular scale in the solution. Among many methods, sol-gel synthesis is particularly promising for production of materials without the need of high-temperature calcination that influence the final properties of the product. ${ }^{[26,27]}$

Concerning these structures, the present study is aimed to obtain cerium titanate compounds as alternative colouring materials to substitute the highly toxic lead, cadmium, chromium and nickel pigments, commonly used in the ceramic industry. This work stresses in the synthetic methodologies (sol-gel route) which allow to obtain mixed oxides with $\mathrm{Ti}(\mathrm{IV}) / \mathrm{Ce}(\mathrm{III}), \mathrm{Ti}(\mathrm{IV}) / \mathrm{Ce}(\mathrm{IV})$ or $\mathrm{Ti}(\mathrm{IV}) / \mathrm{Ce}(\mathrm{III})-\mathrm{Ce}(\mathrm{IV})$ species. A structural, magnetic and spectroscopic characterization of these materials will be performed.

\section{Results and Discussion}

Figure 1 depicts the diffractograms of the samples fired under air at different temperatures. It can be observed that at low temperatures $\left(700\right.$ and $\left.800^{\circ} \mathrm{C}\right)$ there is a unique phase corresponding to the $\mathrm{CeO}_{2}$ structure (JCPDS 78-694). However, at 1000 and $1200^{\circ} \mathrm{C}, \mathrm{TiO}_{2}$ rutile (JCPDS 78-1510) appears as a secondary phase which indicates the crystallization of $\mathrm{TiO}_{2}$ at high temperatures. This behaviour has already been reported by Fang et al. ${ }^{[28]}$ They propose a reaction mechanism on $\mathrm{TiO}_{2}: \mathrm{CeO}_{2}$ mixed oxides based on the formation of a $\mathrm{Ti}: \mathrm{CeO}_{2}$ solid solution at low temperature which presents a low crystallinity of the $\mathrm{TiO}_{2}$ anatase and therefore, XRD pattern only displays the typical pattern of $\mathrm{CeO}_{2}$ with a cubic fluorite structure.

In our system, titanium ions could be either inside $\mathrm{CeO}_{2}$ structure as solid solution, but no significant shift of diffraction peaks has been detected, or as amorphous or nanocrystalline anatase material.

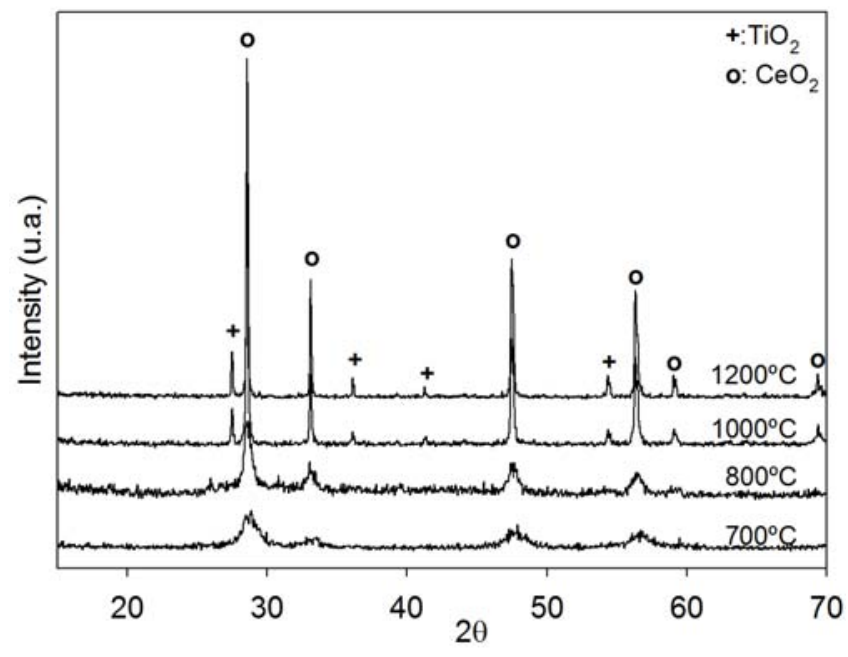

Figure 1. XRD of the samples fired at different temperature

The appearance of the $\mathrm{CeO}_{2}$ phase detected by XRD implies an oxidation of $\mathrm{Ce}^{3+}$ precursor species to $\mathrm{Ce}^{4+}$ ions. The broad peaks observed in the powder XRD pattern (likely the result of limited crystallinity because of the relatively low temperatures necessary to access the phase), as well as a non-negligible background (likely originating from some residual amorphous intermediate) make structure refinement difficult.

Table 1 lists the unit cell parameters of $\mathrm{CeO}_{2}$ calculated from the $\mathrm{XRD}$ data according to a $\mathrm{CeO}_{2}$ fluorite structure (space group $\mathrm{Fm}$ $3 m$ ) using the WinXPow program. ${ }^{[29]}$ The unit cell parameters of cubic $\mathrm{CeO}_{2}$ in the mixed oxide are in all temperatures a little bit smaller than in the pure $\mathrm{CeO}_{2}$, which is indicative of some kind of shrink of the cubic $\mathrm{CeO}_{2}$ unit cell, indicating the incorporation of $\mathrm{Ti}(\mathrm{IV})$ ions. Thus, the interaction between the octahedral $\mathrm{Ti}$ in $\mathrm{TiO}_{2}$ and the eight-fold coordination of the $\mathrm{Ti}$ in $\mathrm{CeO}_{2}$ will inhibit crystallization of rutile until high temperature. ${ }^{[30]}$ At 1000 and 1200 ${ }^{\circ} \mathrm{C}$, the $\mathrm{CeO}_{2}$ cell volume is more similar to the pure $\mathrm{CeO}_{2}$ than at lower temperature indicating that $\mathrm{Ti}$ ions in solid solution migrate from $\mathrm{CeO}_{2}$ to crystallize as $\mathrm{TiO}_{2}$ rutile phase.

From the (llll 111 ) diffraction peak of fluorite $\mathrm{CeO}_{2}$, the average crystallite sizes of $\mathrm{CeO}_{2}$ particles have been calculated using the Debye-Scherrer formula and they are summarized in table 1 . The values confirm a continuous increase in particle size with temperature, ranging from $\approx 7 \mathrm{~nm}\left(700^{\circ} \mathrm{C}\right)$ to $105 \mathrm{~nm}\left(1200{ }^{\circ} \mathrm{C}\right)$.

Table 1. Calculated lattice parameter $a$ at different firing temperature

\begin{tabular}{ccc}
\hline Temperature $\left({ }^{\circ} \mathrm{C}\right)$ & $a(\AA)$ & Crystalline size $(\mathrm{nm})$ \\
\hline $700{ }^{\circ} \mathrm{C}$ & 5.380 & $7.34 \mathrm{~nm}$
\end{tabular}




\begin{tabular}{ccc}
$800{ }^{\circ} \mathrm{C}$ & 5.401 & $18.20 \mathrm{~nm}$ \\
$1000{ }^{\circ} \mathrm{C}$ & 5.407 & $51.89 \mathrm{~nm}$ \\
$1200{ }^{\circ} \mathrm{C}$ & 5.407 & $105.93 \mathrm{~nm}$ \\
$\mathrm{CeO}_{2}$ fluorite $700^{\circ} \mathrm{C}$ & 5.411 & $17.09 \mathrm{~nm}$ \\
\hline
\end{tabular}

The morphology and compositional homogeneity of the particles have been studied by SEM analysis. Special attention has been paid to the samples in which Ti species have not been detected by XRD. Figure 2 displays a SEM micrograph, the representative elemental maps of $\mathrm{Ti}$ and $\mathrm{Ce}$ and an elemental analysis spectrum of the powders fired at $700^{\circ} \mathrm{C}$ under air. The SEM image shows that cerium titanate particles are found in the micrometric scale and do not present any specific morphology. Elemental analysis performed by energy dispersive X-ray (EDX) showed a homogeneous distribution of the elements in the analyzed regions, corresponding to the initial stoichiometry. Moreover, the mapping images indicate that, within the magnification used, no $\mathrm{Ti}$ and $\mathrm{Ce}$ segregated particles are detected since both elements present a uniform distribution, supporting the formation of a Ce-Ti solid solution.
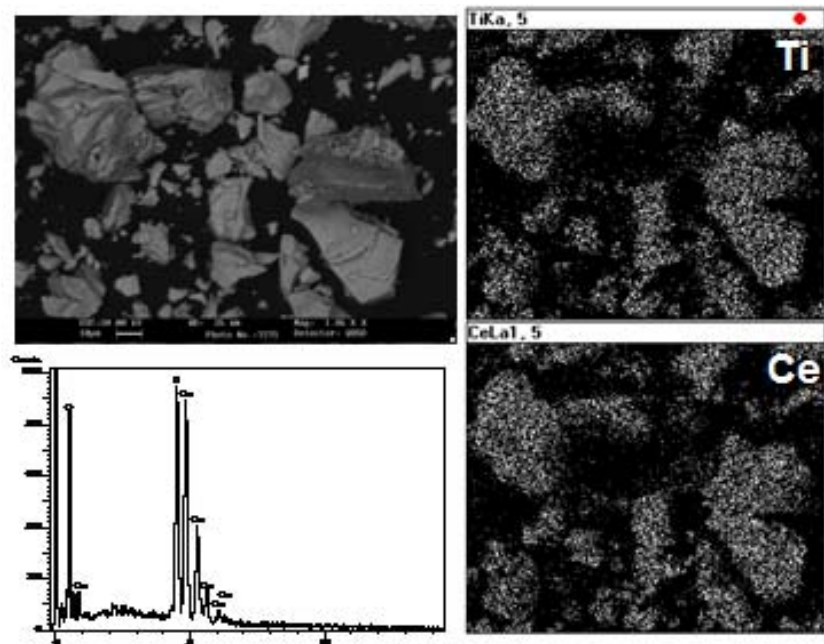

Figure 2. Scanning electron microscopic (SEM) micrograph, Ce and Ti mapping images and EDX spectrum of the sample fired at $700^{\circ} \mathrm{C}$ under air atmosphere

The evolution of the oxygen sublattice with temperature was analyzed by Raman spectroscopy. Figure 3 shows the Raman spectra recorded for the samples after different heat treatments. All the spectra present an important Raman band around $460 \mathrm{~cm}^{-1}$ which can be attributed to the Raman-active mode of $\mathrm{CeO}_{2}$ with the $F_{2 g}$ symmetry. According to theoretical calculations, the cubic $\mathrm{CeO}_{2}$ structure possesses six optical-phonon branches, but only one vibration at around $463 \mathrm{~cm}^{-1}$ (symmetric breathing of the oxygen ions around $\mathrm{Ce}$ ions) is generally detected by spectral measurements, ${ }^{[31]}$ in agreement with our results.

The stretching modes of $\mathrm{TiO}_{2}$ anatase appears at 385,500 and $625 \mathrm{~cm}^{-1} \cdot{ }^{[32]}$ These bands are observed in the spectra recorded up to $800{ }^{\circ} \mathrm{C}$, and all of them disappear at high temperature, which could be attributed to the crystallization of the rutile phase.

In contrast, when the sample is fired at 1000 and $1200^{\circ} \mathrm{C}$, a new band centred arount $610 \mathrm{~cm}^{-1}$ becomes evident. This vibration could be attributed to the $A_{1 g}$ active mode of the rutile, for which four Raman modes are allowed $\left[143 \mathrm{~cm}^{-1}\left(B_{1 \mathrm{~g}}\right), 447 \mathrm{~cm}^{-1}\left(E_{\mathrm{g}}\right), 612\right.$ $\mathrm{cm}^{-1}\left(A_{1 \mathrm{~g}}\right)$ and $\left.826 \mathrm{~cm}^{-1}\left(B_{2 \mathrm{~g}}\right)\right] \cdot{ }^{[33,34]}$ Furthermore, a band around $720 \mathrm{~cm}-1$ increases in intensity with temperature. This vibrational mode could be assigned to seven-coordinate Ti atoms in a fluorite- like structure ${ }^{[35]}$ which indicates the incorporation of titanium ions into the fluorite ceria lattice.

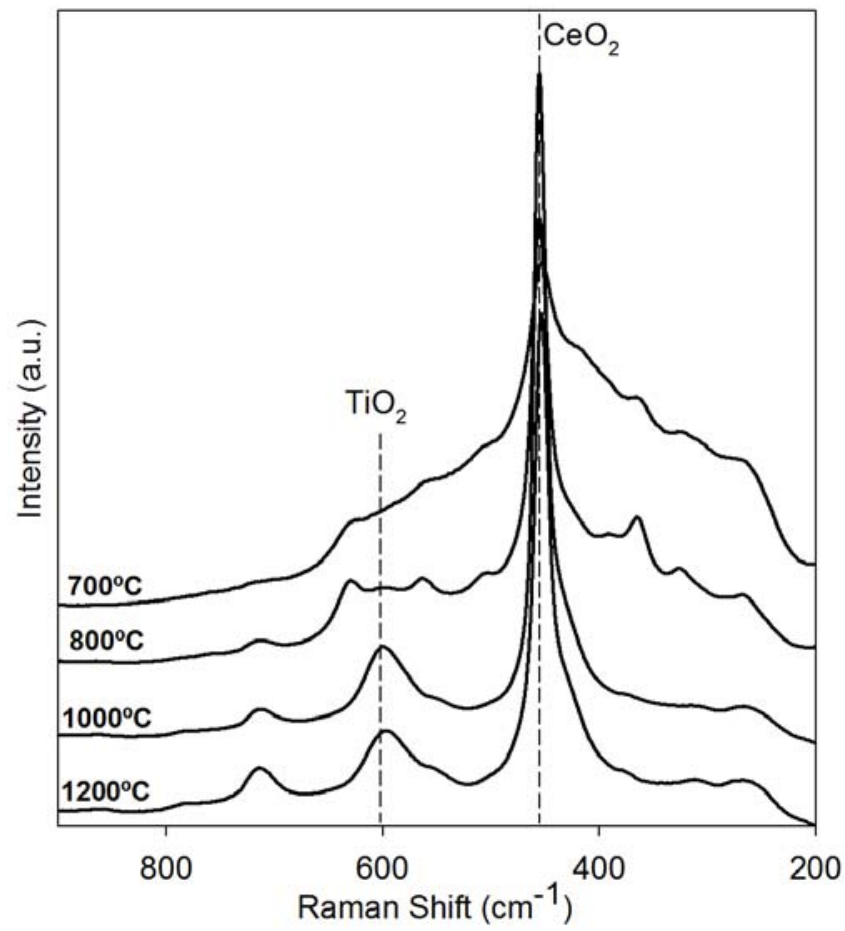

Figure 3. Raman spectra of the samples fired at different temperatures

Once the structural evolution of the $\mathrm{CeO}_{2}-\mathrm{TiO}_{2}$ mixed oxide system with temperature was established, the optical properties of the samples were investigated by UV-visible absorption and luminescence measurements. Figure $4 \mathrm{a}$ illustrates the variation of the $b^{*}$ and $\mathrm{L}^{*}$ coordinates, the yellow and the intensity components in the CIELAB system, respectively. A linear loss in the yellow component $\left(\mathrm{b}^{*}\right)$ of the colour with temperature can be observed, which indicates a regular evolution of the structure; meanwhile $\mathrm{L}^{*}$ remains almost constant.
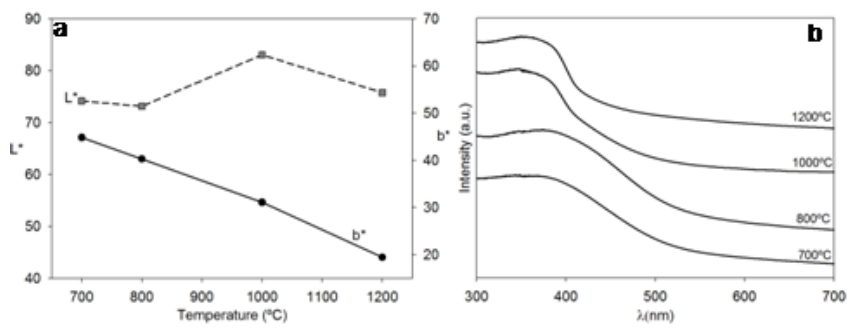

Figure 4 (a) L* and b* chromatic coordinates and (b) UV-visible spectra of the samples with temperature

The UV-Visible spectra of the samples are depicted in figure $4 \mathrm{~b}$. The spectra exhibit a strong absorption band between 300-400 nm. Despite rare earth ions stabilize the trivalent state, as it has been stated before, cerium compounds usually exhibit the coexistence of $\mathrm{Ce}^{3+}$ and $\mathrm{Ce}^{4+}$ species because of its particular electronic configuration. ${ }^{[36,37]}$ The electron donation ability of $\mathrm{Ce}(\mathrm{III})$ facilitates the excitation of an electron from the $4 \mathrm{f}$ to the $5 \mathrm{~d}$ shell, showing characteristic broad bands in the UV region between 330 and $200 \mathrm{~cm}^{-1}$, although the main absorption band is around $310 \mathrm{~cm}^{-}$ ${ }^{1 .}{ }^{[38]}$ By other hand, Ce(IV) favors charge transfer (CT) transitions 
from the host ligands to the rare earth ions. In the case of cerium, $4 \mathrm{f}-5 \mathrm{~d}$ bands of $\mathrm{Ce}^{3+}$ ions and the $\mathrm{CT}$ bands of $\mathrm{Ce}^{4+}$ ions appear in the same wavelength range, what cause them to overlap each other. $^{[39]}$

In our samples, the spectra of those fired at low temperatures $\left(700\right.$ and $800^{\circ} \mathrm{C}$ ) show that the band shifts to higher wavenumber values. This difference clearly indicates a modification in the symmetry and chemical environment of the active cerium ions. We have to bear in mind that at low temperatures, $\mathrm{CeO}_{2}$ fluorite structure is partially occupied by $\mathrm{Ti}$ ions, both located in cubic positions. Since the ionic radius of $\mathrm{Ce}^{4+}$ ions is larger than $\mathrm{Ti}^{4+}$ ions, the unit cell shrinks and $\mathrm{Ce}$ ions possess a constricted environment, making the $\mathrm{Ce}-\mathrm{O}$ bond covalence higher than in a regular cubic structure. The higher covalent character reduces the interaction between the electrons, since they spread out over wider orbitals, and electronic transitions require lower energy, leading to the shift of absorption bands at longer wavelengths.

By other hand, the absorption spectra seem to possess two bands which could be assigned to the presence of $\mathrm{Ce}^{3+}$ and $\mathrm{Ce}^{4+}$ ions simultaneously. Therefore, because of the overlapping of both bands, it is really difficult to determine the specie responsible of color with this optical technique.

Ce(III) ions $\left(4 f^{1}\right)$ presents a characteristic intense blue emission upon UV excitation due to a radiative transition from the excited $5 \mathrm{~d}$ level to the ${ }^{2} \mathrm{~F}$ ground state of the ions. ${ }^{[40]}$ Therefore, in order to corroborate the presence of $\mathrm{Ce}^{3+}$ ions, the fluorescence of the samples was performed. Figure 5 depicts a representative excitation and emission spectra of the sample fired at $700^{\circ} \mathrm{C}$. At all temperatures tested in the present study, samples present similar luminescence behaviour, strengthening the existence of trivalent ions in all cases. The excitation spectrum for $\lambda_{\mathrm{em}}=363 \mathrm{~nm}$ shows a band at $266 \mathrm{~nm}$, which corresponds to optical transitions from the ${ }^{2} \mathrm{~F}_{5 / 2}$ ground state to some of the five higher lying levels of the ${ }^{2} \mathrm{D}$ excited state of $\mathrm{Ce}^{3+}$ in the crystal. ${ }^{[41,42]}$ The emission spectrum recorded upon $\lambda_{\text {exc }}=266 \mathrm{~nm}$ shows the characteristic emission band at $363 \mathrm{~nm}$, which corresponds to the parity-allowed electric dipole transition $5 \mathrm{~d}-4 \mathrm{f}$ after the non-radiative relaxation process inside the non-degenerated ${ }^{2} \mathrm{D}$ lying levels. ${ }^{[43]}$

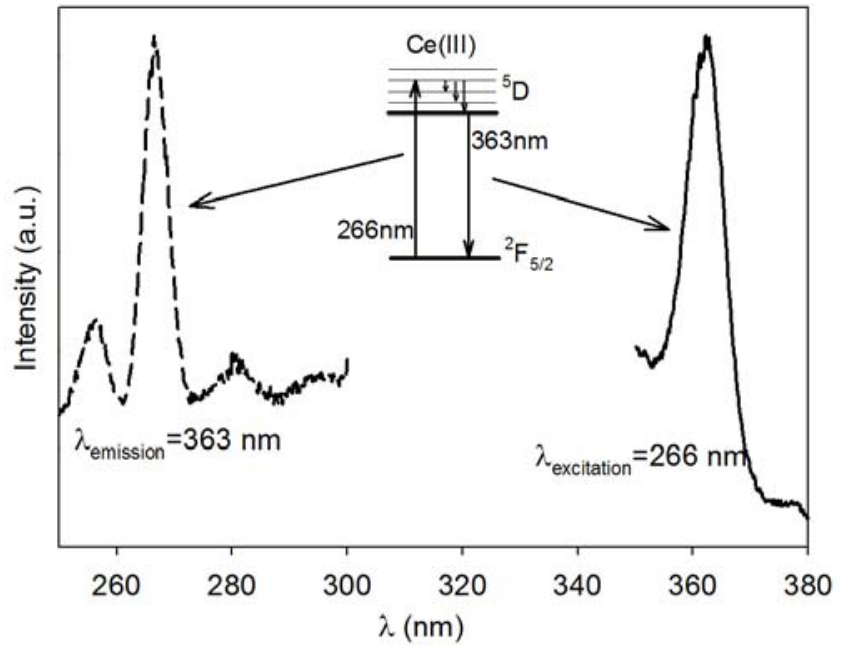

Figure 5. Emission and excitation spectra of the sample $\mathrm{S} 3$ fired at $700^{\circ} \mathrm{C}$ in air.

Although the existence of $\mathrm{Ce}(\mathrm{III})$ has been evidenced from optical results, there is an important oxidation to $\mathrm{Ce}(\mathrm{IV})$ during thermal treatment under air, leading to the crystallization of $\mathrm{CeO}_{2}$ and $\mathrm{TiO}_{2}$. Therefore, reducing firing atmospheres were tested in order to obtain the desired $\mathrm{Ce}_{2} \mathrm{Ti}_{2} \mathrm{O}_{7}$ phase.

\section{- Fired under reducing conditions:}

In order to prevent the oxidation of $\mathrm{Ce}$ (III) ions to $\mathrm{Ce}(\mathrm{IV})$ during firing, the sample was fired at 700 and $1000^{\circ} \mathrm{C}$ under reductive conditions in a $\mathrm{N}_{2} /$ glucose atmosphere. XRD results showed that a $\mathrm{N}_{2}$ /glucose atmosphere does not achieve to avoid the oxidation towards $\mathrm{CeO}_{2}$ since no differences with the samples fired under air were found in the XRD patterns at 700 and $1000{ }^{\circ} \mathrm{C}$ for $2 \mathrm{~h}$ (not shown). Nevertheless, the samples presented a greenish coloration indicative of some kind of change in the species responsible of colour, possibly due to the existence of a higher concentration of trivalent species, which highly affect to the final colour.

In order to elucidate the final oxygen content and the oxidation state of the metallic ions EPR and magnetic measurements have been carried out. We assume all the studied samples have a composition between pyrochlore $\mathrm{Ce}_{2} \mathrm{Ti}_{2} \mathrm{O}_{7}$ and fluorite $\mathrm{Ce}_{2} \mathrm{Ti}_{2} \mathrm{O}_{8}$. Weak EPR signals are observed only for temperatures lower than $50 \mathrm{~K}$. Figure 5 presents the observed spectra at $10 \mathrm{~K}$. For the raw sample, a very broad axial signal is observed covering practically all the magnetic field measured $(10000 \mathrm{G})$, although it can be interpretated with g// aprox. 1.0 and $\mathrm{g}$ (perp) aprox. 2.3. A similar but less intense signal is observed in the spectra of sample fired at $700{ }^{\circ} \mathrm{C}$ under $\mathrm{N}_{2}$-glucose (named $700 \mathrm{~N}_{2}$ ), whereas it is nearly absent in the spectra of the samples fired at 700 and $1000{ }^{\circ} \mathrm{C}$ under air (named 700 and 1000 respectively) and at $1000{ }^{\circ} \mathrm{C}$ under $\mathrm{N}_{2-}$ glucose (named $1000 \mathrm{~N}_{2}$ ). This signal could be attributed to the presence of $\mathrm{Ce}^{3+}$ ions in the samples rather than $\mathrm{Ti}^{3+}$, hence narrow signals at $\mathrm{g}$-values close to 2.0 are expected for this ion. ${ }^{[44]} \mathrm{In}$ fact, the spectra are very similar to those reported by Misra ${ }^{[45]}$ for $\mathrm{Ce}^{3+}$ doped in $\mathrm{Y}_{\left(\mathrm{NO}_{3}\right)_{3}} \cdot 6 \mathrm{H}_{2} \mathrm{O}$ crystals and by Scotti ${ }^{[46]}$ in Ce-doped phosphosilicate glasses. In both cases it has been postulated that $\mathrm{Ce}^{3+}$ ions occupy much distorted octacoordinated sites, with a strong mixing of the various Kramer's doublets arising from the ${ }^{2} \mathrm{~F}_{5 / 2}$ ground state. Furthermore, as the intensity of this signal decreases going from the raw to the samples fired at $1000^{\circ} \mathrm{C}$, it is expected that the concentration of the $\mathrm{Ce}^{3+}$ ions in the samples also decreases in the same sense (see below). This result points to the instability of $\mathrm{Ce}^{3+}$ species in air with increasing firing temperatures, with the result of its oxidation to $\mathrm{Ce}^{\mathrm{IV}}$ and the formation of $\mathrm{CeO}_{2}$. Taking into account that the initial species are $\mathrm{Ce}^{\mathrm{III}}$ and $\mathrm{Ti}^{\mathrm{IV}}$, we could expect the following redox process: ${ }^{[5]}$ $\mathrm{Ce}^{3+}+\mathrm{Ti}^{4+}->\mathrm{Ce}^{4+}+\mathrm{Ti}^{3+}$. The oxidation of $\mathrm{Ce}^{\mathrm{III}}$ without the appearance of an appreciable amount of $\mathrm{Ti}^{\mathrm{iII}}$ ions could be explained according to the following crystallization mechanism: $\mathrm{Ce}^{\mathrm{III}}$ ions tend to segregate and diffuse towards the surface of the $\mathrm{Ce}-\mathrm{Ti}$ mixed oxide during heat treatment. This effect was already demonstrated by XPS measurements ${ }^{[47]}$ and fractal analysis ${ }^{[9]}$ of a series of $\mathrm{CeO}_{2}-\mathrm{TiO}_{2}$ samples. Thus, the cerium species mainly located at the surface of the particles are more accessible than the internal titanium species, and they can be involved in redox processes with the furnace atmosphere.

A weak signal centred at a g-value of 6.8 , which is fully resolved in the $1000^{\circ} \mathrm{C}$ samples. It consists of a narrow feature exhibiting weaker hyperfine satellites $\left(/ \mathrm{A} /=227 \times 10^{-4} \mathrm{~cm}^{-1}\right)$ from a nucleus having nuclear spin $\mathrm{I}=7 / 2$ (Figure 6 , bottom). This set of signals are unambiguously assigned to an impurity of $\mathrm{Er}^{3+}\left({ }^{167} \mathrm{Er}\right.$ isotope abundance is $23 \%, \mathrm{I}=7 / 2$ ) in cubic sites. ${ }^{[48]}$ 


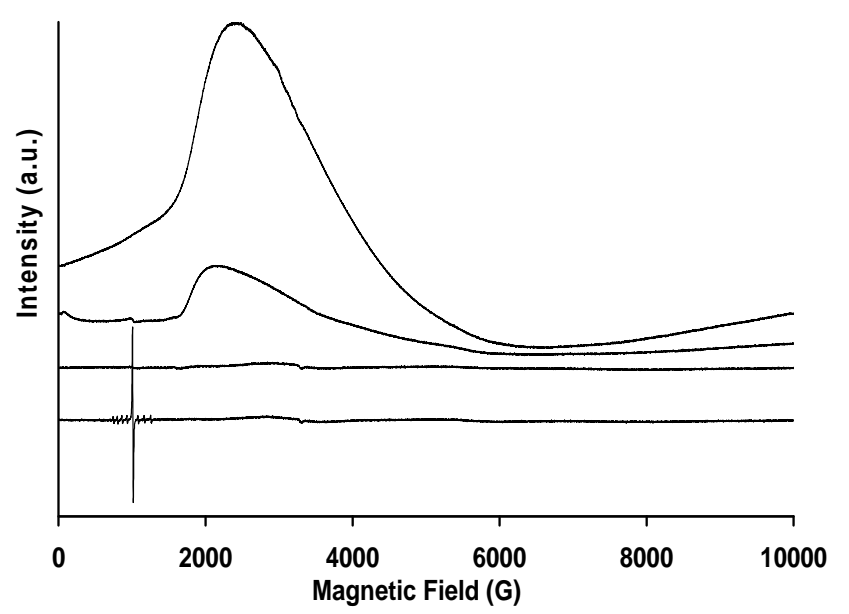

Figure 6. EPR spectra of the studied samples at $10 \mathrm{~K}$. From top, raw, $700 \mathrm{~N}_{2}$-glucose, 700 , and $1000{ }^{\circ} \mathrm{C}$.)

Magnetic measurements results are summarized in Figure 7 as a plot of the product of the susceptibility per mol of $\mathrm{Ce}$ and temperature vs. temperature. The raw sample is clearly paramagnetic and follows a Curie-Weiss law.

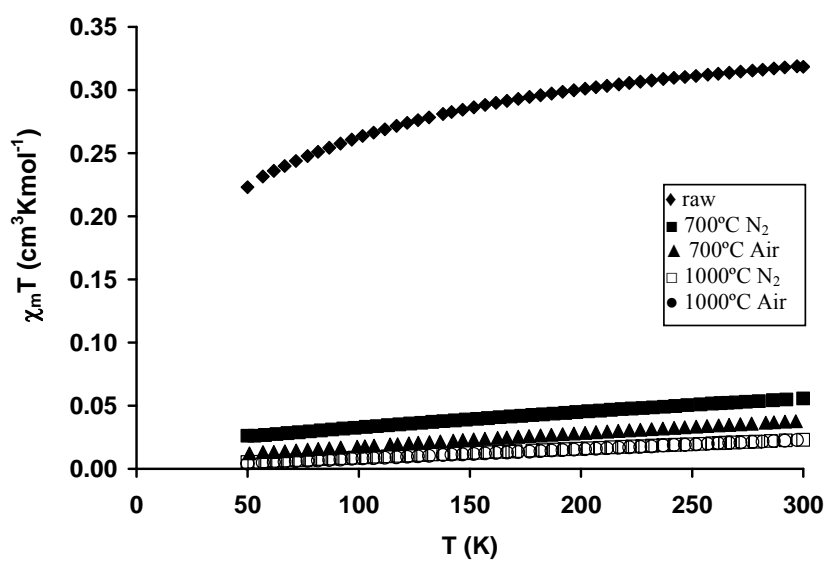

Figure 7. Plot of experimental $\chi_{\mathrm{m}}$. $T$ for the studied samples

From the EPR data we can assume that paramagnetism is due only to $\mathrm{Ce}^{3+}$ and hence the decrease of the $\chi_{\mathrm{m}} \cdot \mathrm{T}$ product when lowering the temperature is easily understood by the depopulation of the higher energy Kramer's doublets arising from the crystal field splitting of the ground state of the lanthanide ion, ${ }^{2} \mathrm{~F}_{5 / 2}$, as observed in most of Ce(III) compounds. ${ }^{[49]}$ Nevertheless, the observed $\chi_{\mathrm{m}} . \mathrm{T}$ product at room temperature is lower than that expected for the free ion of 0.79 or the observed in $\mathrm{Ce}_{2} \mathrm{O}_{3}$ of 0.52 $\mathrm{cm}^{3} \mathrm{~mol}^{-1} \mathrm{~K}^{[51,52]}$ That last value has been used by several authors $^{[50-53]}$ to evaluate the percentage of paramagnetic $\mathrm{Ce}^{3+}$ centers in cerium oxides. Accordingly, taking into account that the sol-gel procedure does not modify the amounts of $\mathrm{Ce}$ and $\mathrm{Ti}$ introduced as precursors (the stoichiometrical formula), we can estimate a percentage of approximately $60 \%$ of $\mathrm{Ce}^{3+}$ in the raw solgel sample leading to a formula of $\mathrm{Ce}_{2} \mathrm{Ti}_{2} \mathrm{O}_{7.4}$. The rest of the samples have much less paramagnetism and majority of cerium is in the tetravalent state. From the susceptibility data we can extract the results indicated in table 2 , in fully accord with the intensity of the signals observed in the EPR spectra.
Table 2. Ce(III) percentage and calculated formula according the susceptibility data

\begin{tabular}{ccc}
\hline Sample & $\mathrm{Ce}(\mathrm{III})$ percentage & Formula \\
\hline raw & 60 & $\mathrm{Ce}_{2} \mathrm{Ti}_{2} \mathrm{O}_{7.4}$ \\
$700 \mathrm{~N}_{2}$ & 12 & $\mathrm{Ce}_{2} \mathrm{Ti}_{2} \mathrm{O}_{7.88}$ \\
700 & 7 & $\mathrm{Ce}_{2} \mathrm{Ti}_{2} \mathrm{O}_{7.93}$ \\
$1000 N_{2}$ & 4 & $\mathrm{Ce}_{2} \mathrm{Ti}_{2} \mathrm{O}_{7.96}$ \\
1000 & 2 & $\mathrm{Ce}_{2} \mathrm{Ti}_{2} \mathrm{O}_{7.98}$ \\
\hline
\end{tabular}

According to the obtained results it was concluded that $\mathrm{N}_{2}$ /glucose atmosphere is not reductive enough to avoid the oxidation of $\mathrm{Ce}$ (III). Thus, a more energetic reductor agent such as $\mathrm{H}_{2}$ was tested. XRD analysis showed interesting changes in the developed phases (Figure 8).

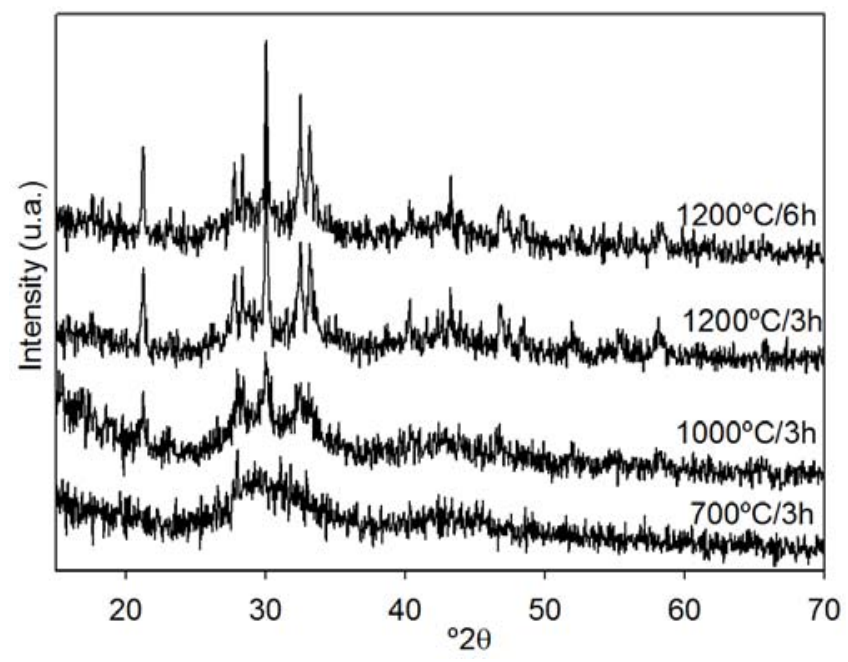

Figure 8. XRD patterns of the samples fired under $\mathrm{N}_{2} / \mathrm{H}_{2}$ atmosphere

At $700{ }^{\circ} \mathrm{C}$ XRD pattern shows the typical feature of an amorphous material. At $1000{ }^{\circ} \mathrm{C}$ an incipient crystallization is observed, however it is not until $1200{ }^{\circ} \mathrm{C}$ when the diffraction peaks can be identified with the $\mathrm{Ce}_{2} \mathrm{Ti}_{2} \mathrm{O}_{7}$ pyrochlore phase (JCPDS 47-667). This structure indicates that the cerium ions are mainly in the trivalent oxidation state. Comparing these patterns with those obtained under an oxidizing atmosphere, a lower crystallinity can be observed. This fact indicates that the amorphous phase (not detected by XRD) still coexists with the well-crystallized pyrochlore structure. A possible reason for this low crystallinity could be attributed to the poor amount of oxygen available in the furnace atmosphere, which acts not only to inhibit CeIII oxidation but also to delay the crystallization process. The difficulty to crystallize $\mathrm{Ce}_{2} \mathrm{Ti}_{2} \mathrm{O}_{7}$ compounds from an amorphous TiIV-CeIII mixed oxide has already been reported. ${ }^{[47]}$ Rietveld refinements cannot be conducted, because of the low crystallinity of the samples and the poor definition of the XRD patterns.

The study of the bond vibrations by Raman spectroscopy corroborates the differences in the structures developed under different atmospheres. Figure 9 depicts the Raman spectra after firing at $1000{ }^{\circ} \mathrm{C}$ under air and reducing atmospheres. It can be seen that the sample fired with $\mathrm{H}_{2}$ presents a different spectrum than the other two spectra which develops the bands corresponding to the $\mathrm{CeO}_{2}$ and $\mathrm{TiO}_{2}$ rutile vibration mode at 460 and $610 \mathrm{~cm}^{-1}$, respectively.

It can be observed that the spectrum recorded for $\mathrm{H}_{2}$-treated sample is not dominated by the bands of $\mathrm{Ce}-\mathrm{O}$ (in $\mathrm{CeO}_{2}$ ) and Ti-O (in $\mathrm{TiO}_{2}$ ) vibrations located at 460 and $610 \mathrm{~cm}^{-1}$, respectively. An 
important change in the profile is detected, with appearance of new bands at $165,190,350$ and $545 \mathrm{~cm}^{-1}$, which can be attributed to the $\mathrm{Ce}_{2} \mathrm{Ti}_{2} \mathrm{O}_{7}$ structure. ${ }^{[54]}$

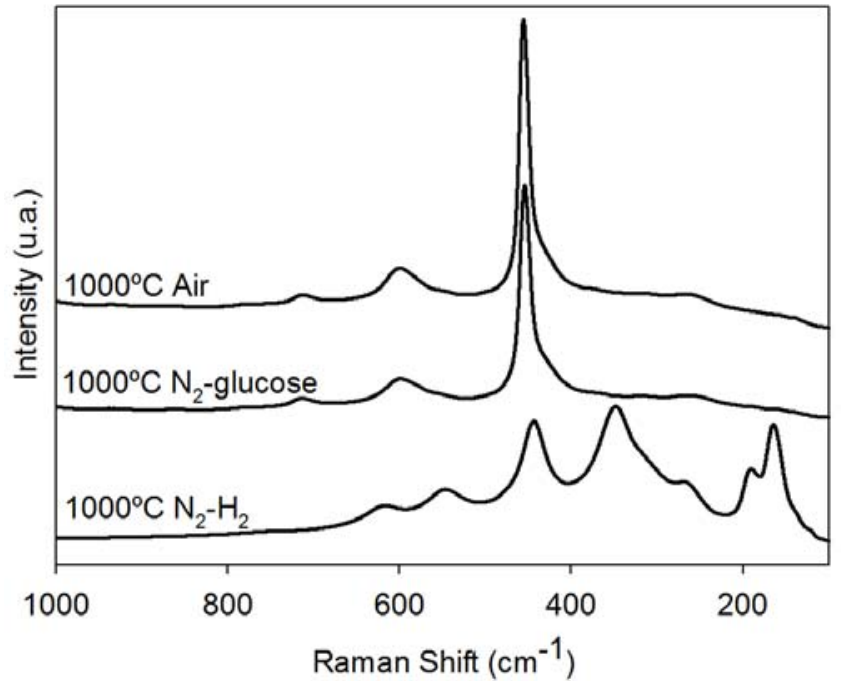

Figure 9. Raman spectra of the samples fired at $1000{ }^{\circ} \mathrm{C}$

Magnetic measurement results for the best-crystallized $\mathrm{Ce}_{2} \mathrm{Ti}_{2} \mathrm{O}_{7}$ sample (calcined at $1200{ }^{\circ} \mathrm{C} / 6 \mathrm{~h}$ under $\mathrm{H}_{2}$ ) is represented in Figure 10. It is easily observed that the sample treated at $1200{ }^{\circ} \mathrm{C}$ is more paramagnetic than those reported in Figure 7. As set out above, we assume that paramagnetism is due mainly to $\mathrm{Ce}^{3+}$ and, hence, the decrease in the $\chi_{\mathrm{m}} \mathrm{T}$ product with decreasing temperatures arises from depopulation of the higher-energy Kramer's doublets. Assuming the same considerations stated above, we can estimate that the percentage of paramagnetic $\mathrm{Ce}^{3+}$ centres in the samples treated at $1000{ }^{\circ} \mathrm{C} / 3 \mathrm{~h} \mathrm{H}_{2}$ (not shown) is about $20 \%$, which leads to a formula of $\mathrm{Ce}_{2} \mathrm{Ti}_{2} \mathrm{O}_{7.8}$. Nevertheless, the observed roomtemperature $\chi \mathrm{mT}$ product for samples treated at $1200{ }^{\circ} \mathrm{C} / \mathrm{H} 2$ for 3 and $6 \mathrm{~h}$ is 0.53 and $0.58 \mathrm{~cm}^{3} \mathrm{~mol}^{-1} \mathrm{~K}$, respectively, which is somewhat higher than the previously cited value of $0.52 \mathrm{~cm}^{3} \mathrm{~mol}^{-}$ ${ }^{1} \mathrm{~K} \cdot{ }^{[51,52]}$ These results could be understood by considering that all the cerium is in the trivalent state and that there is some additional contribution due to the presence of small amounts of titanium also in the trivalent state. In an approximate analysis, by considering the d1 configuration of $\mathrm{Ti}^{3+}$ and the expected spin-only contribution to paramagnetism, we could estimate a percentage of 2 and $16 \%$ of trivalent titanium in those samples, which leads to compositions of $\mathrm{Ce}_{2} \mathrm{Ti}_{2} \mathrm{O}_{6.98}$ and $\mathrm{Ce}_{2} \mathrm{Ti}_{2} \mathrm{O}_{6.84}$, respectively.

These considerations are fully confirmed by EPR measurements (see inset of Figure 10). In fact, the low-temperature spectrum of a sample treated at $1200{ }^{\circ} \mathrm{C} / 6 \mathrm{~h}$ under an $\mathrm{H}_{2}$ atmosphere exhibits new features that are not observed in the spectra of the samples studied above or in the sample treated at $1000{ }^{\circ} \mathrm{C}$ under $\mathrm{H}_{2}$. It consists of weak axial signals with $g_{\perp}=1.97$ and $g_{\|}=1.94$. This kind of spectrum and those $g$ values were assigned in the literature to the presence of $\mathrm{Ti}^{3+}$ defects in the rutile $\mathrm{TiO}_{2}$ phases, ${ }^{[55-57]}$ which confirms the presence of trivalent titanium in our samples.

The use of reductive atmospheres also produces important changes in the body colour of the samples. Table 3 details the different chromatic coordinates of the samples fired under oxidative and reductive atmospheres at 700,1000 and $1200{ }^{\circ} \mathrm{C}$. When the sample is fired in air, it presents a yellow colouration that originates from the $\mathrm{O} 2 p-\mathrm{Ce} 4 f$ chargetransfer transitions, which changes to a green or brown shade after firing under $\mathrm{N}_{2}$-glucose or
$\mathrm{N}_{2}-\mathrm{H}_{2}$, respectively. In the case of the calcination with $\mathrm{N}_{2}-$ glucose, the colouration at $1000{ }^{\circ} \mathrm{C}$ is quite similar to the one treated in air, which agrees with the higher rate of $\mathrm{Ce}^{\mathrm{III}}$ oxidation and the crystallization of $\mathrm{TiO}_{2}$ as shown by XRD. According to these results, the changes in colouration could be related to the different oxidation state of the cerium ions in the samples or to oxygen defects that act as colour centres.

Table 3. Chromatic coordinates of samples fired under different heat treatments

\begin{tabular}{lllll}
\hline Temperature & Atmosphere & $\mathrm{L}^{*}$ & $\mathrm{a}^{*}$ & $\mathrm{~b}^{*}$ \\
\hline $700^{\circ} \mathrm{C}$ & Air & 74.2 & 4.9 & 44.9 \\
$700^{\circ} \mathrm{C}$ & $\mathrm{N}_{2}-\mathrm{Glucose}$ & 47.6 & -0.1 & 11.1 \\
$700^{\circ} \mathrm{C}$ & $\mathrm{N}_{2}-\mathrm{H}_{2}$ & 51.4 & -1.7 & 10.9 \\
\hline $1000^{\circ} \mathrm{C}$ & Air & 83.1 & -1.3 & 31.1 \\
$1000{ }^{\circ} \mathrm{C}$ & $\mathrm{N}_{2}-\mathrm{Glucose}$ & 80.3 & -0.5 & 20.7 \\
$1000^{\circ} \mathrm{C}$ & $\mathrm{N}_{2}-\mathrm{H}_{2}$ & 53.5 & 1.5 & 14.4 \\
\hline $1200^{\circ} \mathrm{C}$ & Air & 75.8 & 2.1 & 19.4 \\
$1200^{\circ} \mathrm{C}$ & $\mathrm{N}_{2}-\mathrm{H}_{2}$ & 46.6 & 5.6 & 11.4 \\
\hline
\end{tabular}

As conclusion, the $\mathrm{Ce}_{2} \mathrm{Ti}_{2} \mathrm{O}_{7}$ structure has been obtained by solgel methodology at lower temperature $\left(1000{ }^{\circ} \mathrm{C} / 3 \mathrm{~h}\right)$ than those reported by other authors ${ }^{[1,18,58]}\left(1200-1300^{\circ} \mathrm{C}\right.$ for several days). It has been demonstrated that the firing process is crucial for the development of the pyrochlore phase since $\mathrm{Ce}(\mathrm{III})$ is easily oxidized to $\mathrm{Ce}(\mathrm{IV})$. Thus, calcination at $1000{ }^{\circ} \mathrm{C}$ under air or soft reducing agents ( $\mathrm{CO}$ from glucose- $\mathrm{N}_{2}$ flow) conduce to the $\mathrm{CeO}_{2}$ and $\mathrm{TiO}_{2}$ crystallization, meanwhile with a $\mathrm{H}_{2}(5 \%)-\mathrm{N}_{2}$ flow the pyrochlore structure is obtained.

The possibility to modulate the $\mathrm{Ce}^{3+} / \mathrm{Ce}^{4+}$ content depending on the firing atmosphere is an important feature for applications in the catalysis and optical fields. The catalytic response will be further investigated. This behaviour, together with the small particle sizes of the powders, makes these compounds potential materials in multifunctional applications.

\section{Conclusions}

This paper reports the synthesis of a rare-earth containing pyrochlore system, $\mathrm{Ce}_{2} \mathrm{Ti}_{2} \mathrm{O}_{7}$. Crystallization of the pyrochlore phase has been corroborated by XRD and Raman spectroscopy. Magnetic and EPR measurements have been performed in order to clarify the oxidation state of cerium ions in the system. The $\mathrm{Ce}_{2} \mathrm{Ti}_{2} \mathrm{O}_{7}$ structure has been obtained by sol-gel methodology at relatively soft conditions under reductive atmosphere. It has been demonstrated that the firing treatment is crucial for the development of the pyrochlore since $\mathrm{Ce}(\mathrm{III})$ is easily oxidized to $\mathrm{Ce}(\mathrm{IV})$. Thus, calcination under air or soft reducing agents conduces to $\mathrm{CeO}_{2}-\mathrm{TiO}_{2}$ compositions (including solid solutions) with yellow to green colorations. In contrast, the use of an aggressive reducing agent such as $\mathrm{H}_{2}$, the pyrochlore structure is obtained, and the colour changes to brownish shades. The oxidation of trivalent to tetravalent cerium ions is compensated by oxygen vacancies, which can cause distortion of the crystal lattice 
affecting in the physical, chemical and optical properties of the final product. The possibility to modulate the $\mathrm{Ce}^{3+} / \mathrm{Ce}^{4+}$ content and particle sizes depending on the firing conditions (temperature and atmosphere) is interesting for applications in the catalysis and optical fields. The methodology reported in this work allows the development of a more ecological coloured material based on rare earth elements and a promising catalytic material.

\section{Experimental Section}

Cerium titanate structure was prepared by sol-gel methodology using $\mathrm{Ce}\left(\mathrm{NO}_{3}\right)_{3} \cdot 6 \mathrm{H}_{2} \mathrm{O}$ and titanium isopropoxide as precursors in the stoichiometric amount, using absolute ethanol as solvent. The great reactivity of titanium isopropoxide requires that the synthesis must be processed with strict control of moisture and conditions of hydrolysis in order to prepare homogeneous gels rather than precipitates. In this sense, in order to control the hydrolysis and condensation reactions of titanium and cerium species, the chemical modification with a chelating ligand such as acetylacetone (acac) was performed in a preliminary study. The role of acac in the solution is to prevent the hydrolysis of Ti(IV) through less hydrolysable M-acac bonds. ${ }^{[59,60]}$ Different Ti/acac ratios were tested for obtaining transparent gels concluding that the optimal conditions were using the Ti:acac ratio of $4: 1$. Thus, once dissolved the cerium precursor in ethanol, acetylacetonate (acac) and titanium isopropoxide were added drop by drop with continuous stirring to the later solution. The respective concentrations of $\mathrm{Ce}$ and $\mathrm{Ti}$ were both of $0.15 \mathrm{~mol} / \mathrm{L} .^{[61]}$

After that, the mixture was refluxed at $70{ }^{\circ} \mathrm{C}$ during 24 hours under a nitrogen atmosphere in order to preserve the solution from the atmosphere humidity. The resulting orange sol led to a transparent gel after evaporation of solvent, which became a powder after drying in IR lamps. The obtained powders were fired under fluxes of different atmospheres (air, $\mathrm{N}_{2}$-glucose and $\mathrm{H}_{2}-\mathrm{N}_{2}$ ) at $700,800,1000$ and $1200{ }^{\circ} \mathrm{C}$ with an annealing time of $2 \mathrm{~h}$ in a Nabertherm electric furnace at a heating rate of $5{ }^{\circ} \mathrm{C} / \mathrm{min}$. The calcination with reductive conditions were carried out in a tubular furnace with a gas flow $\left(\mathrm{N}_{2}\right.$ or $\left.\mathrm{H}_{2}(5 \%)-\mathrm{N}_{2}\right)$. In the calcination under $\mathrm{N}_{2}$-glucose, a crucible filled with glucose is placed in the entrance of the furnace. The oxidized $\mathrm{CO} / \mathrm{CO}_{2}$ products generated from the combustion of the glucose are dragged along the sample with the $\mathrm{N}_{2}$ flow, inducing the reduction of the sample.

\section{Characterization Techniques:}

Phase analysis of the fired samples was performed by X-ray powder diffraction (XRD) with a SIEMENS D5000 diffractometer with $\mathrm{Cu} \mathrm{K} \alpha$ radiation. Data were collected by step-scanning from 15 to $70^{\circ} 2 \theta$ with a step size of $0.05^{\circ} 2 \theta$ and $1.5 \mathrm{~s}$ counting time at each step. The goniometer was controlled by the "SIEMENS DIFFRACT plus" software, which also determined diffraction peak positions and intensities. The instrument was calibrated using an external Si standard.

The Raman spectra were recorded with spectral windows of $3500-100 \mathrm{~cm}^{-1}$ in a Raman Perkin-Elmer System 2000 spectrometer.

UV-visible-NIR spectroscopy and a colorimetric study of the samples were carried out in a CARY 500 SCAN VARIAN spectrophotometer in the 300$1100 \mathrm{~nm}$ range. The diffuse reflectance spectra (DRS) were obtained using an integrating sphere and $\mathrm{BaSO} 4$ as reference. The CIELAB colour parameters $L * a * b *$ were determined by coupling an analytical software for colour measurements to the VARIAN spectrophotometer. The data were registered from 380 to $700 \mathrm{~nm}$ using a PTFE blank as reflecting standard and a D65 standard illuminant. The chromatic coordinates of the samples have been compared with those of a commercial pink pigment used in the ceramic industry. In the CIELAB system, $\mathrm{L} *$ is the lightness axis [black $(0)$ to white $(100)], a *$ is the green $(<0)$ to red $(>0)$, and $b *$ is the blue $(<0)$ to yellow $(>0)$ axis. ${ }^{[62,63]}$

Scanning electron micrographs of the samples were taken on a Scanning Electron Microscope (SEM) Leica, Leo 440 model, equipped with a spectrometer of Energy Dispersion of X-ray (EDX) from Oxford instruments, using the following operational parameters: acceleration voltage $20 \mathrm{kV}$, measuring time $100 \mathrm{~s}$, working distance $25 \mathrm{~mm}$, counting rate $1.2 \mathrm{kcps}$. The samples for microstructural and microanalysis determinations were deposited in an aluminum holder and coated by graphite film.

Polycrystalline powder EPR (X-band, 9.47 GHz) spectra were recorded on a Brucker E580 spectrometer from room temperature to $5 \mathrm{~K}$.

Variable temperature susceptibility measurements were carried out in the temperature range $50-300 \mathrm{~K}$ at an applied magnetic field of $0.1 \mathrm{~T}$ on polycrystalline samples with a Quantum Design MPMS-XL-5 SQUID magnetometer. The susceptibility data were corrected for the sample holder previously measured using the same conditions and for the diamagnetic contributions as deduced by using Pascal's constant tables.

\section{Acknowledgments}

This research was supported by the Spanish Government (MEC: MAT2005-00541) and Bancaixa Foundation-Universitat Jaume I (P1 1B200747) projects. M. Martos and B. Julián specially thank to UJI and MEC for their PhD fellowship and "Ramon y Cajal" program, respectively.

[1] A. V. Shyakhtina, A. V. Levchenko, J. C. C. Abrantes, V. Yu. Bychkov, V. N. Korchak, V. A. Rassulov, L. L. Larina, O. K. Karyagina, L. G.

Shcherbakova, Mater. Res. Bull. 2007, 42, 742.

[2] A. R. West, Solid State Chemistry and Its Applications, Wiley,

Chichester, 1985.

[3] J. C. Boivin, G. Mairesse, Chem. Mater. 1998, 10, 2870.

[4] R. S. Palov, J. B. Carda, V. Blasco, J. M. Hohembergerger, J. Am.

Ceram. Soc. 2002, 85, 1197.

[5] A. Preuss, R. Gruehn, J. Solid State Chem. 1994, 110, 363.

[6] G. V. Bazuev, O. V. Makarova, V. A. Zhilyaev, G. P. Shveikin, Russ. J. Inorg. Chem. 1976, 21, 1447.

[7] B. M. Reddy, A. Khan, P. Lakshmanan, M. Aouine, S. Loridant, J. C.

Volta, J. Phys. Chem. B 2005, 109, 3355.

[8] M. F. Luo, J. Chen, L. S. Chen, J. Q. Lu, Z. C. Feng, C. Li, Chem.

Mater. 2001, 13, 197.

[9] T. López, F. Rojas, R. Alexander-Katz, F. Galindo, A. Balankin, A.

Buljan, J. Solid State Chem. B 2004, 177, 1873.

[10] J. B. Thomson, A. R. Armstrong, P. G. Bruce, J. Am. Chem. Soc. 1996,

$118,11129$.

[11] M. Glerup, O. F. Nielsen, F. W. Polsen, J. Solid State Chem. 2001, $160,25$.

[12] T. Omata, M. Kita, S. Otsuka-Yao-Matsuo, M. Katada, J. Phys. Chem. Solids 2005, 66, 53.

[13] H. Kishimoto, T. Omata, S. Otsuka-Yao-Matsuo, K. Ueda, H. Hosono,

H. Kawazoe, J. Alloys Compd. 2000, 312, 94.

[14]W. C. Marckrodt, M. Fowles, M. A. Morris, European Patent 91.307.165, 1991

[15] R. Higashinaka, H. Fukazawa, Y. Maeno, Phys. Rev. B 2003, 68, 014415.

[16] M. Yashima, M. Takashina, M. Kakihana, M. Yoshimura, J. Am. Ceram. Soc. 1994, 77, 1869.

[17] S. Otsuka-Yao, H. Morikawa, N. Izu, K. Okuda, J. Jpn. Inst. Met. 1995, 59, 1237.

[18] S. Otsua-Yao-Matsuo, T. Omata, M. Yoshimura, J. Alloys Compd. 2004, 376, 262

[19] B. M. Reddy, A. Khan, Y. Yamada, T. Kobayashi, S. Lorindant, J. C. Volta, J. Phys. Chem. B 2003, 107, 5162.

[20] B. M. Reddy, P. Lakshmanan, A. Khan, J. Phys. Chem. B 2004, 108, 16855 .

[21] A. A. Setlur, W. J. Heward, Y. Gao, A. M. Srivastava, R. G. Chandran, M. V. Shankar, Chem. Mater. 2006, 18, 3314.

[22] G. Blasse, A. Bril, Appl. Phys. Lett. 1967, 11, 53.

[23] X. Gong, P. Wu, W. Chen, H. Yang, J. Mater. Res. 1998, 13, 469.

[24] D. Chen, R. Xu, Mater. Res. Bull. 1998, 33, 409.

[25] M. A. Subramanian, Mater. Res. Bull. 1992, 27, 939.

[26] M. Martos, B. Julián, H. Dehouli, D. Gourier, E. Cordoncillo, P.

Escribano, J. Solid State Chem. 2007, 180, 679.

[27] M. Martos, B. Julián-López, E. Cordoncillo, P. Escribano, J. Phys. Chem. B 2008, 112, 2319.

[28] J. Fang, X. Bi, D. Si, Z. Jiang, W. Huang, Appl. Surf. Sci. 2007, 253, 8952. 
[29] Stoe \& Cie, STOE WinXPOW (Version 1.06), Stoe \& Cie GmbH, Darmstadt, Germany, 1999.

[30] K. J. Hadjiivanov, D. G. Kissurski, Chem. Soc. Rev. 1996, 25, 61.

[31]W. H. Weber, K. C. Hass, J. R. McBride, Phys. Rev. B 1993, 48, 178.

[32] S. T. Martin, C. L. Morrinson, M. R. Hoffmann, J. Phys. Chem. 1994, 98, 13695 .

[33] A. Orendorz, A. Brodyanski, J. Lösch, L. H. Bai, Z. H. Chen, Y. K. Le, C. Ziegler, H. Gnaser, Surf. Sci. 2007, 601, 4390.

[34] S. P. S. Porto, P. A. Fleury, T. C. Damen, Phys. Rev. 1967, 154, 522.

[35] K. J. Moreno, A. F. Fuentes, M. Maczka, J. Lanuza, U. Amador, J. Solid State Chem. 2006, 179, 3805 .

[36] A. Pepe, M. Aparicio, S. Ceré, A. Durán, J. Non-Cryst. Solids 2004, $348,162$.

[37] K. Annapurna, R. N. Dwivedi, P. Kundu, S. Buddhudu, Mater. Lett. 2004, 58, 787.

[38] G. U. Zhenan, J. Non-Cryst. Solids 1982, 52, 337.

[39] H. Ebendorff-Heidepriem, D. Ehrt, Opt. Mater. 2000, 15, 7.

[40] L. Huang, X. Wang, H. Lin, X. Liu, J. Alloys Compd. 2001, 316, 256

[41] G. Blasse, B. Grabmaier, Luminescent Materials, Springer, Berlin, 1994.

[42] C. Q. Xu, Z. X. Zheng, W. H. Tang, Y. C. Wu, J. Lumin. 2007, 124, 151.

[43] E. Cordoncillo, F. J. Guaita, P. Escribano, C. Philippe, B. Viana, C. Sanchez, Opt. Mater. 2001, 18, 309.

[44] B. A. Goodman, J. B. Raynor, Adv. Inorg. Chem. Radiat. 1970, 13, 136.

[45] S. K. Misra, S. Ibor, Physica B 1998, 253, 111.

[46] C. Canevali, M. Mattoni, F. Morazzoni, R. Scotti, M. Casu, A.

Musinu, R. Krsmanovic, S. Polizzi, A. Speghini, M. Betlinelli, J. Am. Chem. Soc. 2005, 127, 14681.

[47] J. Rynkowski, J. Farbotko, R. Touroude, L. Hilaire, Appl. Catal A: General 2000, 203, 335-348.

[48] S. A. Al'tshuler, B. M. Kozyrev, Electron Paramagnetic Resonance in Compounds of Transition Elements, 2nd ed., John Wiley \& Sons, 1974.

[49] M. Puchalska, J. Mrozinski, J. Legendziewicz, J. Alloys Compd. 2008, 451,270 .
[50] A. Bensalem, F. Bozon-Verduraz, V. Perrichon, J. Chem. Soc. Faraday Trans. 1995, 91, 2185.

[51] H. Vidal, S. Bernal, J. Kaspar, M. Pijolat, V. Perrinchon, G. Blanco, J.

M. Pintado, R. T. Baker, G. Colon, F. Fally, Catal. Today 1999, 54, 93.

[52] A. Laachir, V. Perrichon, A. Badri, J. Lamotte, E. Catherine, J. C.

Lavalley, J. El Fallah, L. Hilaire, F. Le Normand, E. Quemere, N. S.

Sauvion, O. Touret, J. Chem. Soc. Faraday Trans. 1991, 87, 1601.

[53] J. P. Candy, V. Perrichon, J. Catal. 1984, 89, 93.

[54] M. T. Vandenborre, E. Husson, J. P. Chatry, D. Michel, J. Raman Spectrosc. 1983, 14, 63.

[55] C. P. Kumar, N. O. Gopal, T. C. Wang, M. Wong, S. C. Ke, J. Phys.

Chem. B 2006, 110, 5223.

[56] K. Y. Jung, S. B. Park, S. Ihm, Appl. Catal B 2004, 51, 239.

[57] D. C. Hurum, A. G. Agrios, K. A. Gray, T. Rajh, M. C. Thurnauer, J. Phys. Chem. B 2003, 107, 4545.

[58] L. A. J. Garvie, H. Xu, Y. Wang, R. L. Putnam, J. Phys. Chem. Solids 2005, 66, 902 .

[59] J. Livage, M. Henry, C. Sanchez, Prog. Solid State Chem. 1988, 18, 259.

[60] C. J. Brinker, G. W. Scherer, Sol-Gel Science, Academic Press, 1990. [61] M. Langlet, C. Coutier, J. Fick, M. Audier, W. Meffre, B. Jacquier, R. Rimer, Opt. Mater. 2001, 16, 463.

[62] P. Escribano, J. B. Carda, E. Cordoncillo, Esmaltes y Pigmentos Cerámicos, Enciclopedia Cerámica (3er Tomo), Faenza Editrice Ibérica, Spain, 2001.

[63] E. J. Dilabert, Medida del color; Servicio de Publicaciones, Madrid, Spain, 1982. 
Entry for the Table of Contents

((Key Topic))

Sol-gel synthesis of cerium titanate materials with tunable $\mathrm{Ce}^{3+} / \mathrm{Ce}^{4+}$ content, crystalline structure and optical properties are reported. XRD, Raman spectroscopy and magnetic measurements corroborate the crystallization of $\mathrm{CeO}_{2}-\mathrm{TiO}_{2}$ mixed oxides or $\mathrm{Ce}_{2} \mathrm{Ti}_{2} \mathrm{O}_{7}$ phase. The $\mathrm{Ce}(\mathrm{III})$ oxidation process affects the coloration, leading to ecological pigments with promising applications in catalysis.

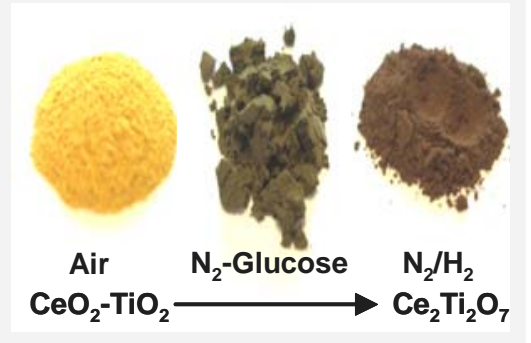

M. Martos*, B. Julián-López, J.V. Folgado, E. Cordoncillo, P. Escribano

Sol-gel synthesis of tunable cerium titanate materials

Keywords: Sol-gel processes/ Cerium/ Rare earth pyrocholore/ Titanates / Nanostructures 